\title{
Frovatriptan versus almotriptan for acute treatment of menstrual migraine: analysis of a double-blind, randomized, cross-over, multicenter, Italian, comparative study
}

\author{
Marco Bartolini - Maria Adelaide Giamberardino - Carlo Lisotto - Paolo Martelletti - Davide Moscato • \\ Biagio Panascia • Lidia Savi - Luigi Alberto Pini - Grazia Sances • Patrizia Santoro • Giorgio Zanchin • \\ Stefano Omboni $\cdot$ Michel D. Ferrari $\cdot$ Brigida Fierro $\cdot$ Filippo Brighina
}

Received: 20 March 2012/ Accepted: 26 April 2012/Published online: 17 May 2012

(c) The Author(s) 2012. This article is published with open access at Springerlink.com

\begin{abstract}
The objective of the study was to compare the efficacy and safety of frovatriptan and almotriptan in women with menstrually related migraine (IHS Classification of Headache disorders) enrolled in a multicenter, randomized, double-blind, cross-over study. Patients received frovatrip$\tan 2.5 \mathrm{mg}$ or almotriptan $12.5 \mathrm{mg}$ in a randomized sequence: after treating 3 episodes of migraine in no more than 3 months with the first treatment, the patient was switched to the other treatment. 67 of the 96 female patients
\end{abstract}

\footnotetext{
M. Bartolini

Clinica Neurologica, Ospedali Riuniti,

Università Politecnica delle Marche, Ancona, Italy

M. A. Giamberardino

Dipartimento di Medicina e Scienze dell'Invecchiamento,

Università "G. D’Annunzio", Chieti, Italy

C. Lisotto

Ospedale Civile San Vito al Tagliamento,

San Vito al Tagliamento, Italy

P. Martelletti

Department of Medical and Molecular Sciences, Sapienza University of Rome and Regional Referral Headache Centre,

Sant'Andrea Hospital, Rome, Italy

D. Moscato

Headache Centre, San Carlo IDI Hospital, Rome, Italy

B. Panascia

Centro Cefalee, A.O. Universitaria Vittorio Emanuele,

Catania, Italy

L. Savi

Department of Neurology, University of Torino, Turin, Italy

\section{A. Pini}

Centro Cefalee, Università degli Studi di

Modena e Reggio Emilia, Reggio Emilia, Italy
}

of the intention-to-treat population of the main study had regular menstrual cycles and were thus included in this subgroup analysis. 77 migraine attacks classified as related to menses were treated with frovatriptan and 78 with almotriptan. Rate of pain relief at 2 and $4 \mathrm{~h}$ was 36 and $53 \%$ for frovatriptan and 41 and $50 \%$ for almotriptan $(p=\mathrm{NS}$ between treatments). Rate of pain free at 2 and $4 \mathrm{~h}$ was 19 and $47 \%$ with frovatriptan and 29 and $54 \%$ for almotriptan $(p=\mathrm{NS})$. At 24 h, $62 \%$ of frovatriptan-treated and $67 \%$ of

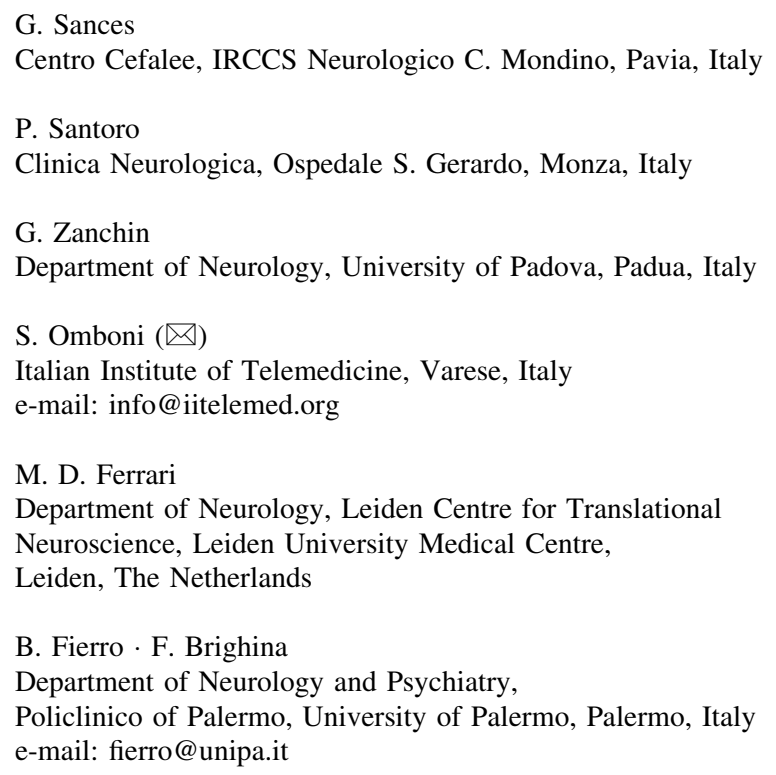


almotriptan-treated patients had pain relief, while 60 versus $67 \%$ were pain free $(p=\mathrm{NS})$. Recurrence at $24 \mathrm{~h}$ was significantly ( $p<0.05$ ) lower with frovatriptan (8vs. $21 \%$ almotriptan). This was the case also at 48 h (9 vs. $24 \%$, $p<0.05)$. Frovatriptan was as effective as almotriptan in the immediate treatment of menstrually related migraine attacks. However, it showed a more favorable sustained effect, as shown by a lower rate of migraine recurrence.

Keywords Migraine - Menstrually related migraine Frovatriptan $\cdot$ Almotriptan

\section{Introduction}

Female migraineurs frequently experience headaches in association with their menstrual cycles [1, 2]. These migraine attacks represent a challenge for both the patient and the headache specialist as they have been shown to be particularly difficult to treat and more disabling than migraines outside of the menstrual period [3].

Triptans are a recommended first-line treatment for moderate to severe migraine, including menstrual migraine $[2,4]$. Sumatriptan, the first triptan to be marketed, has been shown to be well tolerated and effective in providing pain relief in menstrual migraine when administered in the mild pain phase, and also when used in combination with analgesics [5-11]. Second generation triptans such as zolmitriptan [12-14], naratriptan [15], rizatriptan [16-20] and more recently almotriptan [13, 21-24] and frovatriptan [25] have also been successfully tested. Most of these drugs have been found to be effective for treatment or prevention of the acute attack of menstrual migraine [26, 27].

Efficacy of frovatriptan in the short-term prevention or acute treatment of menstrual migraine has been demonstrated in several randomized, double-blind, placebo-controlled or open-label studies [28-34]. In two recently published retrospective analyses of randomized, doubleblind, cross-over, head-to-head trials, frovatriptan provided a more sustained pain relief than zolmitriptan and rizatriptan, with similar pain-free and pain-relief rates at $2 \mathrm{~h}[35,36]$.

The objective of the present study was to add new evidence to the existing body of data through a subgroup analysis of a double-blind, randomized, cross-over study, comparing frovatriptan with almotriptan in a broader group of migraine patients [37].

\section{Methods}

\section{Study population}

The analysis of the subgroup of women suffering from menstrual-related migraine population was pre-defined in the statistical analysis plan and original protocol of the main study [37]. This condition was defined, according to the Appendix of the International Headache Society (IHS) 2004 [38] research criteria, as migraine without aura attacks in a menstruating woman, occurring on day $1 \pm 2$ (namely days -2 to +3 ) of menstruation in at least two out of three menstrual cycles and additionally at other times of the cycle. All subjects had to report at least one, but no more than 6 migraine attacks per month in the 6 months prior to entering the study.

Exclusion criteria are reported in detail in the main study publication [37]. Briefly, women were excluded from the study in case of uncontrolled hypertension, ischemic heart disease, cardiac arrhythmias, previous stroke or transient ischemic attack, severe liver or renal impairment or any other severe or disabling medical condition. History of alcohol or drug abuse, use of anti-migraine drugs, including either test medication for treating one of the last three episodes of migraine, known hypersensitivity to study drugs, previously demonstrated inadequate response to at least two triptans or occurrence of other headaches that have been lasting for more than 6 days, were also considered as exclusion criteria. Pregnancy and breast-feeding precluded participation in the study, while women with childbearing potential but not practicing an effective method of birth control were to be submitted to a pregnancy test, if clinically indicated.

The study was approved by the local institutional review board of the study centers. Written informed consent was provided by all patients before study participation.

\section{Study design}

This was a multicenter, randomized, double-blind, crossover study, including 14 Italian centers (see "Appendix") [37]. Each patient received frovatriptan $2.5 \mathrm{mg}$ or almotriptan $12.5 \mathrm{mg}$ in a randomized sequence: after treating a maximum of 3 episodes of migraine in no more than 3 months with the first treatment, the patient was switched to the other treatment and was asked to treat a maximum of 3 episodes of migraine in no more than 3 months with the second treatment.

Subjects having no migraine episodes during one of the two observation periods were excluded from the study.

After signing written informed consent, subjects provided a medical, treatment and migraine history. A physical and neurological examination and pregnancy test (if appropriate) were performed. Blood pressure and heart rate were measured for all subjects. The degree of migraineassociated disability (MIDAS) questionnaire was also completed. At the end of the visit a headache diary documenting characteristics of headache pain (including its relation with menses) and associated symptoms was 
dispensed with study medication to eligible patients. Subjects were instructed to treat a maximum of 3 migraine episodes within a period of no more than 3 months and then to come for the second visit. At this second visit, use of concomitant medications and occurrence of possible adverse events (obtained from diary card) were checked, blood pressure and heart rate were recorded, and a pregnancy test performed, if deemed necessary. At the end of the second visit a headache diary documenting characteristics of headache pain was dispensed with study medication. The same procedures were carried out at the end of the second study treatment period or at the early withdrawal visit.

Patients were instructed to take one dose of study medication as early as possible after the onset of migraine attack. If insufficient relief had been obtained after $2 \mathrm{~h}$, patients were allowed to take a second dose of study medication, with a maximum daily intake of two doses. In case of insufficient relief one hour after the intake of the second dose of the study medication, patients were allowed to take a rescue medication. Rescue medication could not include triptans, or contain ergotamine or its derivatives.

The study involved three visits and each patient's participation time in the study was not to exceed 6 months from randomization.

Randomization was done by blocks of 4 . Blindness was ensured by the overencapsulation technique, i.e., by inserting study drug tablets in capsules.

\section{Data analysis}

The population of this retrospective analysis consisted of all normally menstruating women randomized to any of the two treatment sequences, enrolled to receive either of the study treatments and having treated at least one episode of menstrual migraine with both medications (intention-totreat population).

The following endpoints were evaluated [37]: (a) the proportion of pain-relief episodes at 2, 4 and $24 \mathrm{~h}$ (a decrease in migraine intensity from severe or moderate to mild or none at 2, 4 and $24 \mathrm{~h}$ ); (b) the proportion of painfree episodes at 2, 4 and $24 \mathrm{~h}$ (absence of migraine episodes at 2, 4 and $24 \mathrm{~h}$ after intake of one dose of study drug); (c) recurrence within $24 \mathrm{~h}$ (episodes pain free at $2 \mathrm{~h}$ and headache of any severity returns within $24 \mathrm{~h}$ ); (d) recurrence within $48 \mathrm{~h}$. Changes in headache intensity (4-point scale from none to severe) from baseline after 2, 4, 24 and $48 \mathrm{~h}$ from study drug intake, were also evaluated.

For continuous variables average values and standard deviation (SD) were calculated. Categorical variables were summarized by computing the absolute value and the frequency (as percentage). Endpoints were compared between groups by generalized estimating equation analysis.
Kaplan-Meier curves for cumulative hazard of recurrence over the $48 \mathrm{~h}$ were also drawn. All statistical tests were performed using a two-sided test with a significance level of 0.05 ( $p$ value).

\section{Results}

The main study population consisted of 114 subjects [37], of which 96 were women. 67 of them treated at least one episode of menstrual migraine with both medications and were thus included in the present analysis.

No statistically significant differences were observed for the main demographic and clinical characteristics of the patients of the whole study population and of the subgroup of women with menstrually related migraine (Table 1 ). The only exception was a significantly $(p<0.05)$ wider use of triptans in the previous 3 months in the women with menstrually related migraine.

A total of 77 attacks (24\% of all attacks) classified as menstrually related migraine were treated with frovatriptan and $78(24 \%)$ with almotriptan.

As indicated in Table 2, the proportion of pain-relief episodes was similar $(p=\mathrm{NS})$ between frovatriptan and almotriptan at $2 \mathrm{~h}$ (36 vs. $41 \%), 4 \mathrm{~h}(53$ vs. $50 \%)$ and $24 \mathrm{~h}(62 \mathrm{vs} .67 \%)$. Also the rate of pain-free episodes at 2 , 4 and $24 \mathrm{~h}$ did not differ between the two treatment groups $(19,47$ and $60 \%$ frovatriptan vs. 29,54 and $67 \%$ almotriptan; $p=\mathrm{NS}$ for both) (Table 2).

The rate of migraine recurrence after $24 \mathrm{~h}$ was lower $(p<0.05)$ with frovatriptan than with almotriptan (8 vs. $21 \%)$. This was the case also for recurrences at $48 \mathrm{~h}(9 \%$ frovatriptan vs. $24 \%$ almotriptan, $p<0.05$ ). Also, the cumulative hazard of recurrence during the follow-up was significantly $(p<0.05)$ lower with frovatriptan, as displayed in Fig. 1.

During the 48-h observation period, migraine intensity was progressively reduced by both drugs, with a statistically significant larger reduction $(p<0.05)$ with frovatriptan than with almotriptan at 24 and 48 h (Fig. 2).

\section{Discussion}

In the present subgroup analysis of a double-blind, randomized, cross-over study [37], acute treatment of menstrually related migraine attacks with frovatriptan and almotriptan was associated with similar proportions of pain-relief and of pain-free episodes at 2, 4 and $24 \mathrm{~h}$ between the two drugs. However, frovatriptan showed significantly lower rates of headache recurrence over the 24 and $48 \mathrm{~h}$ than almotriptan. These results seem to indicate a more prolonged beneficial effect of frovatriptan compared 
Table 1 Demographic and clinical baseline data of the 114 patients of the main study [37] and of the subgroup of 67 women with menstrually related migraine

Data are shown as mean $( \pm \mathrm{SD})$ or absolute $(n)$ and relative frequency $(\%)$

${ }^{\text {a }}$ Numbers refer to number and frequency of attacks as respect to overall number of attacks

\begin{tabular}{llll}
\hline & $\begin{array}{l}\text { Main study } \\
(n=114)\end{array}$ & $\begin{array}{l}\text { Menstruating } \\
\text { women }(n=67)\end{array}$ & $p$ \\
\hline Age (years, means $\pm \mathrm{SD})$ & $40 \pm 10$ & $37 \pm 8$ & NS \\
Height $(\mathrm{cm}$, means $\pm \mathrm{SD})$ & $165 \pm 6$ & $164 \pm 6$ & $\mathrm{NS}$ \\
Weight $(\mathrm{kg}$, means $\pm \mathrm{SD})$ & $65 \pm 12$ & $62 \pm 10$ & $\mathrm{NS}$ \\
Age at onset of migraine (years, means $\pm \mathrm{SD})$ & $18 \pm 8$ & $17 \pm 7$ & $\mathrm{NS}$ \\
Migraine attack duration $>2$ days $(n, \%)$ & $29(25)$ & $16(24)$ & $\mathrm{NS}$ \\
MIDAS score (means $\pm \mathrm{SD})$ & $23 \pm 16$ & $23 \pm 16$ & $\mathrm{NS}$ \\
No use of triptans in the previous 3 months $(n, \%)$ & $93(82)$ & $46(69)$ & $<0.05$ \\
Moderate or severe attacks $(n, \%)^{\mathrm{a}}$ & $532(80)$ & $133(86)$ & $\mathrm{NS}$ \\
Patients with at least one moderate or severe attack $(n, \%)$ & $111(97)$ & $64(96)$ & $\mathrm{NS}$ \\
\hline
\end{tabular}

Table 2 Main study endpoints in the two study treatment groups

\begin{tabular}{llll}
\hline & Frovatriptan & Almotriptan & $p$ \\
\hline Pain-relief episodes at $2 \mathrm{~h}$ & $28(36)$ & $32(41)$ & $\mathrm{NS}$ \\
Pain-free episodes at $2 \mathrm{~h}$ & $15(19)$ & $23(29)$ & $\mathrm{NS}$ \\
Pain-relief episodes at $4 \mathrm{~h}$ & $41(53)$ & $38(50)$ & $\mathrm{NS}$ \\
Pain-free episodes at $4 \mathrm{~h}$ & $36(47)$ & $42(54)$ & $\mathrm{NS}$ \\
Pain-relief episodes at 24 h & $48(62)$ & $53(67)$ & $\mathrm{NS}$ \\
Pain-free episodes at $24 \mathrm{~h}$ & $46(60)$ & $52(67)$ & $\mathrm{NS}$ \\
Recurrent episodes at 24 h & $6(8)$ & $16(21)$ & $<0.05$ \\
Recurrent episodes at $48 \mathrm{~h}$ & $7(9)$ & $19(24)$ & $<0.05$ \\
\hline
\end{tabular}

Data are reported as absolute $(n)$ and relative (\%) frequency. $p$ refers to the statistical significance of the difference between the two study drugs

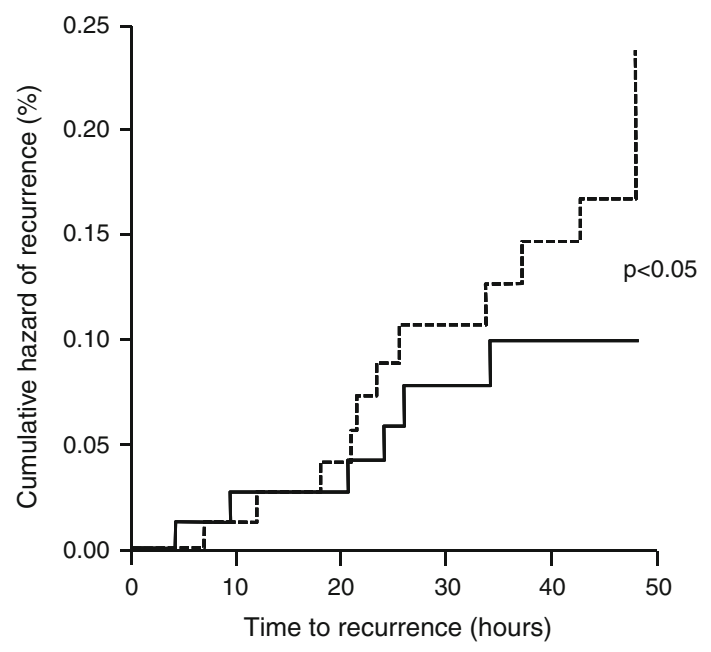

Fig. 1 Cumulative hazard of recurrence over the $24 \mathrm{~h}$ during treatment with frovatriptan (continuous line) or almotriptan (dashed line) in the 67 women with menstrually related migraine included in this analysis. The $p$ value refers to the statistical significance of the between-treatment difference

to almotriptan, probably because of the different pharmacokinetics of the two drugs. Frovatriptan has a longer halflife than almotriptan (25-26 h vs. 3-4 h), which probably explains why frovatriptan has been reported to have a

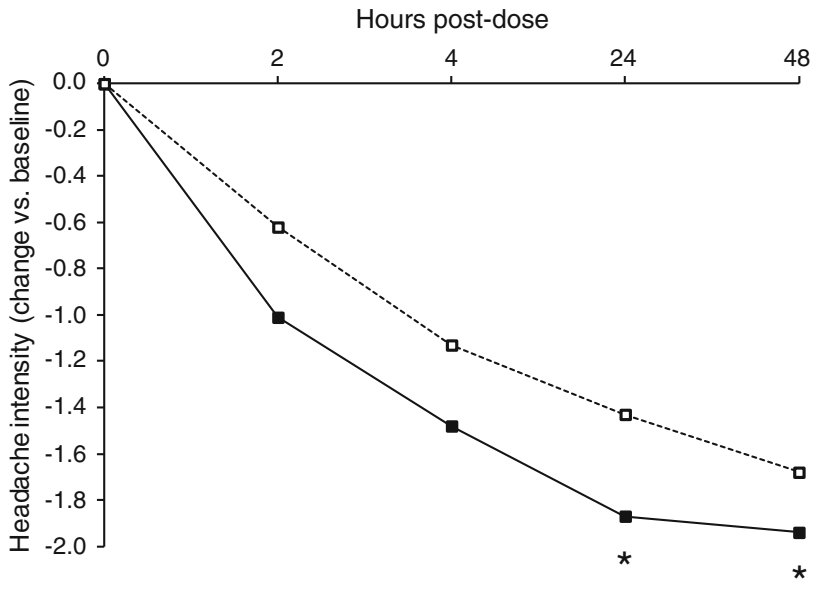

Fig. 2 Changes in migraine intensity from baseline during treatment with frovatriptan (continuous line) or almotriptan (dashed line) in the 67 women with menstrually related migraine included in this analysis. The asterisks refer to the statistical significance of the betweentreatment difference $\left({ }^{*} p<0.05\right)$

lower incidence of migraine recurrence than almotriptan [39-42]. Differences between the two drugs in this regard might be further enhanced in the subgroup of women with menstrually related migraine, who are known to suffer from a more disabling form of migraine as compared to non-menstrual migraineurs [1-3].

Results of our study corroborate those of previous randomized, placebo-controlled or open-label studies, which proved the efficacy of frovatriptan in the short-term prevention [28-32] or acute treatment of menstrual migraine [33-36]. Our results also provide more evidence and confirm results of previous almotriptan-based trials. In a retrospective analysis of a multicenter, multinational, randomized, double-blind parallel clinical trial, including 136 women treating a menstrual migraine attack with almotriptan, $68 \%$ of subjects had obtained pain relief and $45 \%$ were pain free at $2 \mathrm{~h}$, while recurrence rates between 2 and $24 \mathrm{~h}$ after dosing were $33 \%$ [13]. In another post hoc analysis of a multicenter, double-blind, parallel group, 
placebo-controlled trial almotriptan treatment in 97 women with menstrually related migraine resulted in $2 \mathrm{~h}$ pain relief, $2 \mathrm{~h}$ pain free and sustained pain-free rates of 77, 35 and $23 \%$, respectively [21]. Finally, in a recent randomized, double-blind, placebo-controlled cross-over study, including 74 premenopausal women with menstrually related migraine, almotriptan was associated with a significantly higher percentage of patients free of pain at $2 \mathrm{~h}$ compared with placebo (48 vs. $26 \%$ ). In this study, overall $36 \%$ of patients were found to be sustained pain free with almotriptan versus $17 \%$ with placebo [22]. The proportions achieved for study endpoints in almotriptan-treated patients in the trials cited above were slightly higher than those observed in our study.

Our study was the first directly comparing the efficacy of frovatriptan and almotriptan for the acute treatments for menstrually related migraine. In previous publications, frovatriptan showed pain-relief and pain-free rates at 2 and $24 \mathrm{~h}$ similar to those of rizatriptan and zolmitriptan, but significantly lower rates of recurrences at $24 \mathrm{~h}$ (15 vs. $22 \%$ zolmitriptan and 10 vs. $32 \%$ rizatriptan) $[35,36]$. In another head-to-head double-blind, randomized trial comparing almotriptan with zolmitriptan, no significant differences between the two treatments were found, with similar pain-relief rates at $2 \mathrm{~h}$ (68 vs. $69 \%$ ), similar painfree rates at $2 \mathrm{~h}(45$ vs. $41 \%)$ and similar recurrences at 2-24 h (33 vs. $35 \%$ ) [13].

In conclusion, results of the present analysis of data from a multicenter, randomized, double-blind, head-tohead, cross-over study suggest that frovatriptan and almotriptan are similarly effective in the immediate treatment of acute attack of menstrually related migraine. However, since frovatriptan seems to be superior to almotriptan in providing sustained relief from pain, this may suggest the use of the former in those patients with long-duration or high frequency of recurrence of migraine attacks. In the light of our results, we would indicate the use of frovatriptan in women with menstrual migraine, but with the caution of avoiding drug overuse or misuse, e.g. by limiting its use to more severe perimenstrual attacks. This will prevent occurrence of adverse events and progression and chronification of migraine, a risk which is directly related to the number of days with symptomatic drug intake.

We acknowledge that the retrospective nature of our analysis makes subsequent double-blind, randomized, prospective, large clinical trials mandatory to support our data.

Acknowledgments The present study was supported by Laboratori Guidotti.

Conflict of interest All authors have occasionally served as scientific consultants for manufacturers of frovatriptan or almotriptan.
Open Access This article is distributed under the terms of the Creative Commons Attribution License which permits any use, distribution, and reproduction in any medium, provided the original author(s) and the source are credited.

\section{Appendix: List of study sites}

\section{Coordinator: Prof. B. Fierro (Palermo)}

Investigators: M. Bartolini (Ancona), M.A. Giamberardino (Chieti), C. Lisotto (San Vito al Tagliamento), P. Martelletti (Roma), D. Moscato (Roma), B. Panascia (Catania) L. Savi (Torino), L.A. Pini (Reggio Emilia), G. Sances (Pavia), P. Santoro (Monza), G. Zanchin (Padova), B. Fierro (Palermo).

\section{References}

1. Martin VT, Lipton RB (2008) Epidemiology and biology of menstrual migraine. Headache 48(Suppl 3):S124-S130

2. Taylor FR (2009) Clinical aspects of perimenstrual headaches. Curr Pain Headache Rep 13:75-81

3. Allais G, Castagnoli Gabellari I, De Lorenzo C, Mana O, Benedetto C (2007) Menstrual migraine: clinical and therapeutical aspects. Expert Rev Neurother 7:1105-1120

4. Mannix LK, Files JA (2005) The use of triptans in the management of menstrual migraine. CNS Drugs 19:951-972

5. Facchinetti F, Allais G, Nappi RE, Gabellari IC, Di Renzo GC, Genazzani AR, Bellafronte M, Roncolato M, Benedetto C (2010) Sumatriptan (50 mg tablets vs. $25 \mathrm{mg}$ suppositories) in the acute treatment of menstrually related migraine and oral contraceptiveinduced menstrual migraine: a pilot study. Gynecol Endocrinol 26:773-779

6. Mannix LK, Martin VT, Cady RK, Diamond ML, Lener SE, White JD, Derosier FJ, McDonald SA (2009) Combination treatment for menstrual migraine and dysmenorrhea using sumatriptan-naproxen: two randomized controlled trials. Obstet Gynecol 114:106-113

7. Schreiber CP, Cady RK (2007) Diagnosis of menstrual headache and an open-label study among those with previously undiagnosed menstrually related migraine to evaluate the efficacy of sumatriptan $100 \mathrm{mg}$. Clin Ther 29(Suppl):2511-2519

8. Dowson AJ, Massiou H, Aurora SK (2005) Managing migraine headaches experienced by patients who self-report with menstrually related migraine: a prospective, placebo-controlled study with oral sumatriptan. J Headache Pain 6:81-87

9. Landy S, Savani N, Shackelford S, Loftus J, Jones M (2004) Efficacy and tolerability of sumatriptan tablets administered during the mild-pain phase of menstrually associated migraine. Int J Clin Pract 58:913-919

10. Nett R, Landy S, Shackelford S, Richardson MS, Ames M, Lener M (2003) Pain-free efficacy after treatment with sumatriptan in the mild pain phase of menstrually associated migraine. Obstet Gynecol 102:835-842

11. Salonen R, Saiers J (1999) Sumatriptan is effective in the treatment of menstrual migraine: a review of prospective studies and retrospective analyses. Cephalalgia 19:16-19

12. Tuchman M, Hee A, Emeribe U, Silberstein S (2006) Efficacy and tolerability of zolmitriptan oral tablet in the acute treatment of menstrual migraine. CNS Drugs 20:1019-1026 
13. Allais G, Acuto G, Cabarrocas X, Esbri R, Benedetto C, Bussone G (2006) Efficacy and tolerability of almotriptan versus zolmitriptan for the acute treatment of menstrual migraine. Neurol Sci 27(Suppl 2):S193-S197

14. Loder E, Silberstein SD, Abu-Shakra S, Mueller L, Smith T (2004) Efficacy and tolerability of oral zolmitriptan in menstrually associated migraine: a randomized, prospective, parallelgroup, double-blind, placebo-controlled study. Headache 44:120 130

15. Massiou H, Jamin C, Hinzelin G, French Naramig Collaborative Study Group (2005) Efficacy of oral naratriptan in the treatment of menstrually related migraine. Eur J Neurol 12:774-781

16. Bigal M, Sheftell F, Tepper S, Tepper D, Ho TW, Rapoport A (2008) A randomized double-blind study comparing rizatriptan, dexamethasone, and the combination of both in the acute treatment of menstrually related migraine. Headache 48:1286-1293

17. Nett R, Mannix LK, Mueller L, Rodgers A, Hustad CM, Skobieranda F, Ramsey KE (2008) Rizatriptan efficacy in ICHD-II pure menstrual migraine and menstrually related migraine. Headache 48:1194-1201

18. Martin V, Cady R, Mauskop A, Seidman LS, Rodgers A, Hustad CM, Ramsey KE, Skobieranda F (2008) Efficacy of rizatriptan for menstrual migraine in an early intervention model: a prospective subgroup analysis of the rizatriptan TAME (Treat A Migraine Early) studies. Headache 48:226-235

19. Silberstein SD, Massiou H, McCarroll KA, Lines CR (2002) Further evaluation of rizatriptan in menstrual migraine: retrospective analysis of long-term data. Headache 42:917-923

20. Silberstein SD, Massiou H, Le Jeunne C, Johnson-Pratt L, McCarroll KA, Lines CR (2000) Rizatriptan in the treatment of menstrual migraine. Obstet Gynecol 96:237-242

21. Diamond ML, Cady RK, Mao L, Biondi DM, Finlayson G, Greenberg SJ, Wright P (2008) Characteristics of migraine attacks and responses to almotriptan treatment: a comparison of menstrually related and nonmenstrually related migraines. Headache 48:248-258

22. Allais G, Bussone G, D'Andrea G, Moschiano F, d'Onofrio F, Valguarnera F, Manzoni GC, Grazzi L, Allais R, Benedetto C, Acuto G (2011) Almotriptan $12.5 \mathrm{mg}$ in menstrually related migraine: a randomized, double-blind, placebo-controlled study. Cephalalgia 31:144-151

23. Bussone G, Allais G, Castagnoli Gabellari I, Benedetto C (2011) Almotriptan for menstrually related migraine. Expert Opin Pharmacother 12:1933-1943

24. Lionetto L, Fiorillo M, Martelletti P (2011) Efficacy and tolerability of almotriptan in menstrual migraine: a comment. Expert Opin Pharmacother 12:2279-2281

25. Newman LC, Harper S, Jones BA, Campbell J (2009) Frovatriptan for acute treatment of migraine associated with menstruation: results from an open-label postmarketing surveillance study. J Womens Health (Larchmt) 18:1265-1273

26. MacGregor EA (2010) Prevention and treatment of menstrual migraine. Drugs 70:1799-1818

27. Pringsheim T, Davenport WJ, Dodick D (2008) Acute treatment and prevention of menstrually related migraine headache: evidence-based review. Neurology 70:1555-1563
28. MacGregor EA, Pawsey SP, Campbell JC, Hu X (2010) Safety and tolerability of frovatriptan in the acute treatment of migraine and prevention of menstrual migraine: results of a new analysis of data from five previously published studies. Gend Med 7:88-108

29. Brandes JL, Poole A, Kallela M, Schreiber CP, MacGregor EA, Silberstein SD, Tobin J, Shaw R (2009) Short-term frovatriptan for the prevention of difficult-to-treat menstrual migraine attacks. Cephalalgia 29:1133-1148

30. Silberstein SD, Berner T, Tobin J, Xiang Q, Campbell JC (2009) Scheduled short-term prevention with frovatriptan for migraine occurring exclusively in association with menstruation. Headache 49:1283-1297

31. Silberstein SD, Elkind AH, Schreiber C, Keywood C (2004) A randomized trial of frovatriptan for the intermittent prevention of menstrual migraine. Neurology 63:261-269

32. Guidotti M, Mauri M, Barrilà C, Guidotti F, Belloni C (2007) Frovatriptan vs. transdermal oestrogens or naproxen sodium for the prophylaxis of menstrual migraine. J Headache Pain 8:283288

33. Balbisi EA (2006) Frovatriptan: a review of pharmacology, pharmacokinetics and clinical potential in the treatment of menstrual migraine. Ther Clin Risk Manag 2:303-308

34. Allais G, Bussone G, Airola G, Borgogno P, Gabellari IC, De Lorenzo C, Pavia E, Benedetto C (2008) Oral contraceptiveinduced menstrual migraine. Clinical aspects and response to frovatriptan. Neurol Sci 29(Suppl 1):S186-S190

35. Allais G, Tullo V, Benedetto C, Zava D, Omboni S, Bussone G (2011) Efficacy of frovatriptan in the acute treatment of menstrually related migraine: analysis of a double-blind, randomized, multicenter, Italian, comparative study versus zolmitriptan. Neurol Sci 32(Suppl 1):S99-S104

36. Savi L, Omboni S, Lisotto C, Zanchin G, Ferrari MD, Zava D, Pinessi L (2011) Efficacy of frovatriptan in the acute treatment of menstrually related migraine: analysis of a double-blind, randomized, cross-over, multicenter, Italian, comparative study versus rizatriptan. J Headache Pain 12:609-615

37. Bartolini M, Giamberardino MA, Lisotto C, Martelletti P, Moscato D, Panascia B, Savi L, Pini LA, Sances G, Santoro P, Zanchin G, Omboni S, Ferrari MD, Brighina F, Fierro B (2011) A double-blind, randomized, multicenter, Italian study of frovatriptan versus almotriptan for the acute treatment of migraine. J Headache Pain 12:361-368

38. Headache Classification Subcommittee of the International Headache Society (2004) The international classification of headache disorders, 2nd edn. Cephalalgia 24(Suppl 1):9-160

39. Loder E (2010) Triptan therapy in migraine. N Engl J Med 363:63-70

40. Balbisi EA (2004) Frovatriptan succinate, a 5-HT1B/1D receptor agonist for migraine. Int J Clin Pract 58:695-705

41. Antonaci F, De Cillis I, Cuzzoni MG, Allena M (2010) Almotriptan for the treatment of acute migraine: a review of early intervention trials. Expert Rev Neurother 10:351-364

42. Negro A, Lionetto L, Casolla B, Lala N, Simmaco M, Martelletti P (2011) Pharmacokinetic evaluation of frovatriptan. Expert Opin Drug Metab Toxicol 7:1449-1458 